\title{
The association between functional and morphological assessments of endothelial function in patients with rheumatoid arthritis: a cross-sectional study
}

\author{
Aamer Sandoo ${ }^{1,2^{*}}$, James Hodson ${ }^{4}$, Karen M Douglas ${ }^{1}$, Jacqueline P Smith ${ }^{1}$ and George D Kitas ${ }^{1,2,3}$
}

\begin{abstract}
Introduction: Patients with rheumatoid arthritis (RA) are at an increased risk for cardiovascular disease (CVD). One of the earliest manifestations of CVD is endothelial dysfunction (ED), which can lead to functional and morphological vascular abnormalities. Several non-invasive assessments of vascular function and morphology can be utilised to assess vascular health, but little is known about the association between each of these assessments in patients with RA, and they tend to be used interchangeably in the literature. The objective of the present study was to examine associations between measures of vascular function and morphology in patients with RA.
\end{abstract}

Methods: A total of 201 RA patients (155 females, median ( $25^{\text {th }}$ to $75^{\text {th }}$ percentile) age: 67 (59 to 73$)$ ) underwent assessments of microvascular endothelium-dependent and endothelium-independent function (laser Doppler imaging with iontophoresis of acetylcholine and sodium-nitroprusside respectively), macrovascular endotheliumdependent and endothelium-independent function (flow-mediated dilatation and glyceryl-trinitrate-mediated dilation respectively), and vascular morphology (pulse wave analysis, carotid intima-media thickness (cIMT), and carotid plaque).

Results: Spearman's correlations revealed that from the functional parameters, only macrovascular endotheliumindependent function was inversely associated with cIMT $(-0.294(P<0.001))$ after applying the Bonferroni correction for multiple comparisons. For carotid plaque, $t$ tests showed that macrovascular endotheliumindependent function was lower in patients with plaque than without $(15.5 \pm 8.3$ vs. $23.1 \pm 9.1 \%, P=0.002$, respectively).

Conclusions: With the exception of macrovascular endothelium-independent function, all other measures of vascular function were not associated with vascular morphology. This suggests that different assessments of vascular function and morphology in patients with RA reflect quite distinct mechanisms and phases of the atherosclerotic process and should not be used interchangeably.

\section{Introduction}

The endothelium is the innermost layer of the vasculature and is responsible for maintaining an atheroprotective environment within the vessel. Damage to the endothelium from injurious stimuli such as oxidative stress and inflammatory mediators results in endothelial

\footnotetext{
* Correspondence: aamer.sandoo@dgh.nhs.uk

'Department of Rheumatology, Dudley Group of Hospitals NHS Trust,

Russells Hall Hospital, Pensnett Road, Dudley, DY1 2HQ, UK

Full list of author information is available at the end of the article
}

dysfunction (ED) [1]. ED occurs in the early stages of atherosclerosis, and reflects a reduction in the anti-atherogenic molecule, nitric oxide (NO) [2]. In a healthy vessel, $\mathrm{NO}$ is tonically released by endothelial cells to modulate vasomotion, and counter the effects of pro-atherogenic molecules such as endothelin-1 (ET-1) [1]. However, continued reduction in NO levels allows ET-1 to increase, resulting in vascular inflammation and subsequent plaque development $[3,4]$. These vascular alterations can lead to a loss in vasodilatory function, arteriosclerosis, and 
development of advanced atherosclerosis. Several noninvasive assessments of vascular function and morphology can examine different stages of sub-clinical atherosclerosis and provide useful information on an individual's CVD risk status.

During early atherosclerosis, a reduction in NO bioavailability results in reduced vasodilatation along with the promotion of platelet aggregation and leukocyte adhesion to the vascular wall $[5,6]$. Assessments which stimulate endothelial release of NO can be used to examine vasodilatory function in the peripheral circulation and serve as an index of early vascular damage [1]. Endothelial function should be examined in the microvasculature and the macrovasculature due to heterogeneous responses to stimulation between these vascular beds [7]. At present, the gold standard assessment of peripheral endothelial function in the microvasculature is laser Doppler imaging with Iontophoresis of NO agonists and in the macrovasculature is flow-mediated dilatation (FMD) (endothelium-dependent) and glyceryltrinitrate-mediated dilatation (GTN) (endothelium-independent) [1]. These assessments correlate well with assessments of coronary endothelial function [8-10]. Studies have shown that changes in endothelial function are usually transient [11] and can be reversed with treatment [12].

If factors that reduce NO bioavailability are not appropriately controlled then endothelial dysfunction can progress to arteriosclerosis (arterial stiffness) [13]. Arterial stiffness typically occurs in medium to large arteries and is due to degeneration of elastin fibres and deposition of collagen into the vascular wall [14]. A reduction in NO bioavailability and loss of smooth muscle tone also lead to arteriosclerosis, which suggests that this stage of atherosclerosis involves both functional and morphological alterations to the vascular wall [15]. Arterial stiffness can be measured using pulse wave analysis (PWA), which measures the pulse pressure wave in the radial artery and then calculates the central aortic pressure waveform [1]. The consequences of arterial stiffening include insufficient myocardial perfusion leading to angina and myocardial infarction, and left ventricular hypertrophy, which results in heart failure [14]. Arterial stiffness also associates with a number of CVD risk factors such as ageing, smoking, dyslipidemia and hypertension [16], and correlates with assessments of the coronary vasculature [17].

Assessment of advanced, but subclinical, atherosclerosis can be carried out by examination of carotid artery intima-media thickness (cIMT) and by determining the presence of carotid plaques [1]. Thickening of the medial layer of the vessel reflects several atherosclerotic processes that stem from a reduction in NO levels and the concomitant elevation in ET-1 levels; this leads to increased production of pro-inflammatory cytokines, leukocyte adhesion, activation of thrombotic factors, proliferation of smooth muscle cells and formation of lipid-rich plaques [18]. High-resolution B mode ultrasonography is typically used to visualise the carotid artery in different anatomical locations and is a good predictor of future cardiac events in patients with early atherosclerosis [19]. Recent evidence also suggests that determining the susceptibility for plaque rupture may be an additional and important factor to consider when examining subclinical atherosclerosis [20].

Rheumatoid arthritis (RA) is a chronic systemic inflammatory musculoskeletal disease [21]. Patients with RA have an elevated risk of cardiovascular disease (CVD) possibly due to similarities in the inflammatory process in RA and atherosclerosis [22]. There is ample evidence of both functional and morphological abnormalities in the vasculature in RA [12]. At present, little is known on whether assessments of vascular function and morphology can be used interchangeably to provide an index of global endothelial function in RA or whether they should only be used to reflect the distinct stages of atherosclerosis. Indeed, associations between functional and morphological assessments are evident in some cross-sectional studies (see Table 1) [23-25], but studies examining the longitudinal effects of anti-inflammatory medication in RA reveal that some aspects of vascular function, but not morphology, may improve after treatment [26-28]. This suggests that vascular function and morphology might be distinctly affected by RA.

In other populations there is conflicting evidence on whether such assessments correlate with each other (see Table 1). In healthy participants, the majority of studies report no association between functional and morphological vascular assessments [29-32], but some studies in patients with coronary artery disease (CAD) and diabetes find associations between vascular function and morphology $[33,34]$. However, the findings of these studies are difficult to interpret due to a difference in population characteristics (for example age, gender) and technical aspects of measurement (for example automated or manual vascular boundary detection) between studies.

To the best of our knowledge, there are no studies that have specifically examined correlations between microvascular endothelial function and morphological abnormalities in the vasculature, despite research suggesting that inflammatory mediators produced as a result of microvascular injury may contribute to the formation of atherosclerotic lesions in the macrovessels [35]. In addition, several studies report that endothelium-independent function may be more readily affected by CVD risk factors in patients with cardiovascular disease $[36,37]$ and in RA [38], yet there is a dearth of studies examining the relationship between endothelium-independent function 
Table 1 Studies assessing the relationship between functional and morphological measures of endothelial function.

\begin{tabular}{|c|c|c|c|}
\hline Authors & Participants & Vascular assessment & Associations \\
\hline \multicolumn{4}{|l|}{ Healthy } \\
\hline Juonala et al. 2004 [52] & 2109 healthy (age: $32 \pm 5$ years) & FMD, CIMT & FMD inversely associated with CIMT \\
\hline Yeboah et al. 2008 [29] & 2338 healthy (age $78 \pm 4$ ) & FMD, CIMT & No significant associations \\
\hline Koivistoinen et al. 2012 [30] & $\begin{array}{l}1754 \text { healthy (young) (age: } 30-45 \text { ) } \\
\& 336 \text { healthy (older) (age: } 46-76 \text { ) }\end{array}$ & FMD, PWV, cIMT & No significant associations \\
\hline Lunder et al. 2012 [50] & 100 healthy males (age: $42 \pm 6$ ) & FMD, GTN, PWV, CIMT & FMD inversely associated with PWV \\
\hline Irace et al. 2006 [31] & 77 healthy & FMD, GTN, CIMT & No significant associations \\
\hline Yan et al. 2005 [32] & 1,578 healthy males (age: $49 \pm 10$ ) & FMD, GTN, CIMT & No significant associations \\
\hline \multicolumn{4}{|l|}{ Coronary artery disease } \\
\hline Rohani et al. 2005 [39] & 58 CAD (age: $67 \pm 9$ ) & FMD, CIMT, carotid plaque & No significant associations \\
\hline Simova et al. 2008 [33] & 198 CAD (age: $60 \pm 10$ & FMD, CIMT & FMD inversely associated with cIMT \\
\hline Furumoto et al. 2002 [34] & 45 CAD (age: $61 \pm 11$ ) & FMD, GTN, CIMT & FMD inversely associated with cIMT \\
\hline Hashimoto et al. 1999 [53] & $\begin{array}{l}\text { 34 CAD males (age: } 61 \pm 2 \text { ) \& } 33 \\
\text { age-matched healthy controls }\end{array}$ & FMD, GTN, CIMT & $\begin{array}{c}\text { FMD inversely associated with cIMT when both } \\
\text { populations combined, and when analysis was } \\
\text { performed in healthy controls only } \\
\& \\
\text { GTN inversely associated with cIMT when both } \\
\text { populations combined }\end{array}$ \\
\hline $\begin{array}{l}\text { Enderle et al. } 1998 \\
{[54]}\end{array}$ & $\begin{array}{l}101 \text { CAD (age: } 60 \pm 8.6 \text { ) \& } 21 \text { non- } \\
\text { CAD (age: } 57 \pm 8.2 \text { ) }\end{array}$ & FMD, GTN, CIMT & FMD inversely associated with cIMT \\
\hline \multicolumn{4}{|l|}{ Diabetes } \\
\hline $\begin{array}{c}\text { Ravikumar et al. } 2002 \\
\text { [55] }\end{array}$ & $\begin{array}{l}50 \text { diabetics (age: } 54 \pm 10 \text { ) \& } 50 \\
\text { healthy age- \& sex-matched } \\
\text { controls }\end{array}$ & FMD, Alx, cIMT & $\begin{array}{c}\text { FMD inversely associated with Alx and cIMT } \\
\text { when both populations combined, and when } \\
\text { analysis was performed in healthy controls only } \\
\& \\
\text { FMD inversely associated with Alx in diabetics }\end{array}$ \\
\hline \multicolumn{4}{|l|}{ Rheumatoid arthritis } \\
\hline Arosio et al. 2007 [23] & 65 RA females (age: 41 - 52) & FMD, PWV & FMD inversely associated with $\mathrm{PWV}$ in RA \\
\hline Kerekes et al. 2008 [25] & 52 RA (age: $51 \pm 12$ ) & FMD, GTN, CIMT & FMD inversely associated with CIMT \\
\hline $\begin{array}{c}\text { Soltesz et al. } 2009 \\
\text { [24] }\end{array}$ & $\begin{array}{l}101 \text { patients with autoimmune } \\
\text { disease (age: } 52 \pm 13 \text { ) }\end{array}$ & FMD, Alx, PWV, cIMT & $\begin{array}{l}\text { FMD inversely associated with Alx, PWV and } \\
\text { CIMT }\end{array}$ \\
\hline Van Doornum et al. 2003 & 25 RA (age: $46 \pm 8$ ) & FMD, GTN, PWA & FMD not associated with PWA \\
\hline
\end{tabular}

[60]

Alx, augmentation index; cIMT, carotid intima-media thickness; CAD, coronary artery disease; FMD, flow-mediated dilatation; GTN, glyceryl-trinitrate mediated dilatation; PWV, pulse wave velocity; RA, rheumatoid arthritis.

and morphological parameters. Moreover, there is only one small study in patients with CAD that has assessed associations between macrovascular endothelial function and presence of plaque, and found no association [39]. The prevalence of plaque is increased in RA [20], and further research examining vascular predictors of plaque is required.

The aim of the present study was to examine whether microvascular and macrovascular endothelial function associate with arteriosclerosis and carotid atherosclerosis in order to understand whether these distinct assessments of atherosclerosis are independent or related to each other in patients with RA.

\section{Methods}

A total of 201 consecutive RA patients were recruited from the rheumatology outpatient clinics of the Dudley
Group NHS Foundation Trust, United Kingdom. All patients met the retrospective application of the 1987 revised RA criteria of the American College of Rheumatology [40]. The study received ethics approval from The Black Country Research Ethics Committee. All participants gave their written informed consent according to the Declaration of Helsinki.

\section{Protocol}

Patients reported to a temperature-controlled vascular laboratory $\left(22^{\circ} \mathrm{C}\right)$ after a 12 -hour overnight fast. All patients underwent a detailed clinical examination and demographic information was collected by questionnaire. The disease activity score in 28 joints (DAS28) [41] was also calculated. Following this, patients underwent several functional and morphological vascular assessments including laser Doppler imaging with 
Iontophoresis of acetylcholine (ACh) and sodium nitroprusside (SNP)(microvascular endothelial function), FMD and GTN (macrovascular endothelial function), PWA (augmentation index (AIx)), cIMT as well as assessment of carotid plaque (carotid atherosclerosis).

\section{Microvascular endothelial function}

Endothelial function of the microvasculature was assessed non-invasively using LDI (Moor LDI 2 SIM; Moor Instruments Ltd, Axminster, UK) with iontophoresis of 1\% ACh (Miochol-E; Novartis, Frimley, UK) and 1\% SNP (Nitroprussiat Fides, Rottapharm Madaus, Barcelona, Spain) in $2.5 \mathrm{ml}$ solution containing $0.5 \%$ saline by a single observer (AS). The technique was performed according to previously established guidelines [42] and has been described in detail previously [43]. Briefly, after a baseline scan, 10 scans were recorded during iontophoresis of the vasoactive agents using a $30 \mu \mathrm{A}$ current, followed by two scans during recovery. This technique has an intra-observer co-efficient of variation (CV) for $\mathrm{ACh}$ and SNP of $6.5 \%$ and $5.9 \%$ respectively in our laboratory.

\section{Macrovascular endothelial function}

Assessment of macrovascular endothelium-dependent function was performed using FMD with high-resolution ultrasonography of the brachial artery (Acuson Antares ultrasound system, Siemens PLC, Camberley, UK) according to previously established guidelines [44]. Endothelium-independent responses were examined by administration of a 500 microgram sublingual glyceryltrinitrate (GTN) tablet (Alpharma, Barnstaple, UK). The intra-observer CV for the study ultrasonographer (AS) was $10.7 \%$ for FMD and $11.8 \%$ for GTN assessments respectively. For all vascular tests, endothelial function was expressed as the percentage increase in perfusion or diameter from baseline, and all analysis was carried out offline by AS who was blinded to the identity of the patient.

\section{Pulse wave analysis}

Pulse wave analysis (SphygmoCor Px Pulse Wave Analysis, ScanMed Medical Instruments, Moreton in Marsh, UK) was used to determine AIx as previously described [45]. In brief, an applanation tonometer was positioned over the left radial artery to measure the central aortic waveform. The waveform is calibrated against the brachial blood pressure and contains information on the AIx (calculated as the difference between the second and first systolic peaks and is expressed as a percentage of the pulse pressure). The pressure waveforms in the radial artery were recorded for an 11-second period. The software integrated in the analyser displayed an operator index that reflects the quality of the recorded waveform. If the operator index was low $(<75)$, another reading was taken. Three readings with an operator index $>75$ were used for analysis. For each parameter, the average of the three readings was calculated.

\section{Carotid atherosclerosis}

High-resolution ultrasonography of the carotid artery was performed by an experienced ultrasonographer (AS) according to previously established guidelines [46] using a $10 \mathrm{MHz}$ linear array probe attached to the same highresolution ultrasound scanner as for the FMD assessment. The cIMT was defined by determining the thickness between the lines of Pignoli; with the first echogenic line representing the lumen-intima interface, and the second line representing the media-adventitia interface [47]. Assessments of cIMT were performed in the far wall, $1 \mathrm{~cm}$ proximal to the carotid bulb at sites free of plaque in both the right and left common carotid arteries using the longitudinal scanning plane. Three measurements were taken on each side, and these were averaged to give the mean IMT for the right and left carotid arteries separately. The IMT from both sides were further averaged to give the overall IMT.

The presence of carotid plaque was identified by scanning the right and left common carotid artery, as well as the internal and external carotid arteries. Carotid plaques were defined as a focal structure encroaching into the arterial lumen of at least $0.5 \mathrm{~mm}$ or $50 \%$ of surrounding IMT value, or an IMT value of $>1.5 \mathrm{~mm}$ [46]. The relative echogenicity of the plaques were evaluated using the Artery Measurement Software (AMS, Stockholm, Sweden), which is an automated software specifically developed for analysis of gray-scale median (GSM) as previously described [48]. Analysis of cIMT and the presence of plaque were performed by a single observer (AS) who was blinded to the identity of the patient. The intra-observer CV for CIMT was $8.6 \%$.

\section{Statistical analysis}

Statistical analysis was performed using IBM SPSS version 20 (IBM Corp., Armonk, NY, USA). Continuous variables were tested for normality, and expressed as median ( 25 to $75^{\text {th }}$ percentile values) or mean \pm standard deviation, as applicable, with binary variables expressed as percentages. Spearman's correlation coefficients were used to assess the relationships between functional and morphological parameters of endothelial dysfunction. Associations between presence of carotid plaque (dependent variable) and other vascular parameters (independent variables) were then assessed using $t$ tests and Mann-Whitney tests, as appropriate. A $P$ value of 0.05 was deemed to be indicative of significance, although this was Bonferroni corrected where necessary to account for multiple comparisons. Power 
calculations indicated that, for the intended sample size, a correlation coefficient of 0.25 could be detected between functional and structural assessments of endothelial function at $80 \%$ power, with alpha of 0.006 (equivalent to 0.05 after Bonferroni adjustment for eight comparisons). For the effect of carotid plaque, detectable differences in the functional assessments of endothelial function ranged from $33 \%$ to $50 \%$, at $80 \%$ power with alpha of 0.006 .

\section{Results}

The patient characteristics are presented in Table 2. The majority of patients were female, had long disease duration but moderate disease activity levels. The median percentage increase in perfusion to ACh was 201\% (quartiles: 103 to 390), and for SNP was 132\% (56 to 218). In the macrovasculature, mean FMD values were $10.6 \pm 7.1 \%$, and the GTN values were $21.7 \pm 9.0 \%$. Assessment of PWA revealed that the mean AIx was $32.8 \pm 9.1 \%$. Assessment of carotid atherosclerosis yielded a mean cIMT score of $0.69 \pm 0.14 \mathrm{~mm}$, with 16 patients showing evidence of plaque in the right carotid artery, and 15 patients showing plaque in the left carotid artery.

Spearman correlations were used to examine associations between functional and morphological parameters of endothelial function. This analysis revealed only one significant correlation, after adjustment for multiple comparisons, with GTN being inversely associated with cIMT (Table 3). For carotid plaque, it was found that plaques in the right carotid artery were significantly associated with percentage dilation to GTN (Table 4). Where plaque was present in the right carotid artery, the mean GTN was $15.5 \pm 8.3$, compared to $23.1 \pm 9.1$ where no plaque was evident $(P=0.002)$.

Table 2 General and disease-related characteristics for the rheumatoid arthritis patients.

\begin{tabular}{lc}
\hline & $\begin{array}{c}\text { Rheumatoid arthritis } \\
\text { patients }\end{array}$ \\
\hline General characteristics & $67(59-73)$ \\
Age (years) & $155(77)$ \\
Sex female N (\%) & $28(24-32)$ \\
Body mass index & \\
Disease-related characteristics & $16(11-25)$ \\
Disease duration (years) & $113(81)$ \\
Rheumatoid factor positive N (\%)* & $3.1(2.5-4.0)$ \\
DAS28 & $3(2.9-8.5)$ \\
C-reactive protein (mg/l) & $12(5-23)$ \\
Erythrocyte sedimentation rate & \\
(mmhr)
\end{tabular}

Results are expressed as median (25th to 75th percentile values) or number (percentage). *Data only available for 140 patients. DAS28, disease activity score in 28 joints.

\section{Discussion}

The findings of the present study reveal that, in RA, only macrovascular endothelium-independent function associated with carotid atherosclerosis - a marker of advanced morphological vascular alterations. To the best of our knowledge, only two studies have directly examined associations between endothelial function and carotid atherosclerosis in RA, with both studies reporting associations between macrovascular endothelium-dependent function and cIMT $[24,25]$. However, in one study [24] a heterogeneous sample of patients presenting with a variety of autoimmune diseases (RA: $n=14$ ) were recruited, which does not allow for direct comparisons to the present work. In the other study [25], only a small sample of RA patients were assessed $(n=52)$ and macrovascular endothelium-dependent function was considerably lower than those reported in our study $(5 \%$ and $11 \%$ respectively); thus, it is possible that in patients with preserved macrovascular endothelium-dependent function, an association with carotid atherosclerosis is unlikely.

Studies examining the longitudinal effects of antiinflammatory medication in RA have revealed that microvascular and macrovascular endothelium-dependent function, but not vascular morphology, improved following treatment [26-28]. Furthermore, patients with early RA, showed adverse changes in cIMT at 18-month follow-up relative to baseline, but no change in macrovascular endothelium-dependent function [49]. A similar effect is present when examining functional aspects of the microvasculature and the macrovasculature [38]. Taken together, these findings support the present findings and suggest that RA-associated systemic inflammation may exert differential effects on vascular function and morphology in RA.

Studies in other populations have yielded mixed findings; in healthy participants, five out of the six studies included in Table 1 reported no significant associations between macrovascular endothelium-dependent function and carotid atherosclerosis [29,30,32,50,51]. Only Juonala and colleagues [52] reported an association between macrovascular endothelium-dependent function and carotid atherosclerosis, but their study was confounded by a high CV (26\%) for the macrovascular endotheliumdependent function measurement, which may affect the accuracy of their data. In patients with CAD, one study found no association between macrovascular endothelium-dependent function and carotid atherosclerosis [39], with other studies reporting associations between vascular function and morphology $[33,34,53,54]$. However, these studies do have caveats and should therefore be interpreted with caution. For example, Simova and colleagues [33] found only a weak correlation between functional and morphological parameters and this was no longer significant when adjusting for presence of $\mathrm{CAD}$, number 
Table 3 Correlations between functional and structural assessments of endothelial function.

\begin{tabular}{llc}
\hline & Arterial stiffness & Carotid intima-media thickness \\
\hline Microvascular endothelial function & & $-0.159(P=0.043)^{*}$ \\
ACh (\%) & $-0.027(P=0.729)$ & $-0.055(P=0.487)$ \\
SNP (\%) & $0.049(P=0.524)$ & $-0.131(P=0.104)$ \\
Macrovascular endothelial function & & $-0.294(P<0.001)^{* *}$ \\
FMD (\%) & $0.170(P=0.028)^{*}$ & $0.025(P=0.671)$ \\
GTN (\%) & & \\
\hline
\end{tabular}

Data displayed as Spearman's rho coefficient ( $P$ value). ${ }^{*}$ Significant at $P<0.05 ;{ }^{*}$ significant after Bonferroni adjustment for eight comparisons at $P<0.006$. ACh, acetylcholine; SNP, sodium nitroprusside; FMD, flow-mediated dilatation; GTN, glyceryl-trinitrate mediated dilatation.

of diseased coronary arteries and percentage coronary artery stenosis [33]. In addition, some of the studies included only small sample sizes $(n=34$ to 101$)$ $[34,53,54]$, or only found associations when combining patients and healthy controls, but not in patients alone $[53,55]$. The use of manual detection (rather than automated detection) of the vascular wall also decreased accuracy of obtained data in three of the studies [33,34,53]. Finally, the inconsistent findings between studies may also be due to publication bias in the literature; with studies that find no association between functional and morphological parameters less likely to be published. This may have important implications for future study designs and hypotheses.

The absence of an association between functional and morphological assessments of the vasculature may be due to a time lag between endothelial dysfunction and subsequent lesion development. In the study by Hashimoto and colleagues [53], several participants with atherosclerosis had normal cIMT, but decreased macrovascular endothelium-dependent function, thus highlighting that functional abnormalities may precede morphological abnormalities. Indeed, when examining only functional parameters, microvascular dysfunction often precedes macrovascular dysfunction in RA [56] and in diabetes [57], with both vascular beds being independent from each other in RA [58]. Interestingly, one study reported an association between intima-media thickness of the brachial and carotid arteries, but no association between brachial artery endotheliumdependent function and carotid atherosclerosis [39]. This suggests that functional and morphological abnormalities reflect distinct atherosclerotic processes.

In the present study, macrovascular endothelium-independent function associated with carotid atherosclerosis. Such an association was not surprising as both assessments (to varying degrees) reflect a reduction in smooth muscle relaxation, smooth muscle hypertrophy as well as proliferation of smooth muscle cells [1]. Nevertheless, the association highlights the importance of assessing smooth muscle dysfunction in patients at risk of CVD. In healthy individuals with presence of CVD risk factors, macrovascular endothelium-independent dysfunction can occur independently of endothelium-dependent dysfunction [36]. Furthermore, macrovascular endotheliumindependent function, but not macrovascular endothelium-dependent function was related to a reduction in systolic blood pressure (SBP) after 12 and 24 weeks of anti-hypertensive treatment in patients with hypertension [37]. Previous work in RA has also revealed that macrovascular endothelium-independent function associates with several classical CVD risk factors [38], all of which are implicated in the development of carotid artery lesions [59]. Collectively, these findings suggest that abnormalities in macrovascular endothelium-independent function can occur without concomitant abnormalities in macrovascular endothelium-dependent function, and that macrovascular endothelium-independent function is related to morphological changes in the vasculature. However, further detailed prospective studies examining this relationship are warranted.

Table 4 Effect of plaque on functional assessments of endothelial function.

\begin{tabular}{|c|c|c|c|c|c|c|}
\hline & \multicolumn{3}{|c|}{ Evidence of left plaque } & \multicolumn{3}{|c|}{ Evidence of right plaque } \\
\hline & No & Yes & $P$ value & No & Yes & $P$ value \\
\hline \multicolumn{7}{|c|}{ Microvascular endothelial function } \\
\hline $\mathrm{ACh}(\%)$ & $242.5(128.3-454.5)$ & $179.5(95.5-274.5)$ & 0.092 & $262.0(130.7-462.0)$ & $152.0(102.3-214.3)$ & $0.032^{*}$ \\
\hline SNP (\%) & $144.0(75.5-243.5)$ & $120.0(23.0-205.0)$ & 0.221 & $140.5(74.0-244.0)$ & $143.0(58.8-223.8)$ & 0.700 \\
\hline \multicolumn{7}{|c|}{ Macrovascular endothelial function } \\
\hline FMD (\%) & $10.8 \pm 7.2$ & $10.5 \pm 9.1$ & 0.866 & $10.9 \pm 7.4$ & $9.7 \pm 6.8$ & 0.537 \\
\hline GTN (\%) & $22.7 \pm 9.2$ & $17.2 \pm 9.7$ & 0.061 & $23.1 \pm 9.1$ & $15.5 \pm 8.3$ & $0.002^{* *}$ \\
\hline
\end{tabular}

Microvascular endothelial function data displayed as: median (quartiles), with $P$ values from Mann-Whitney tests. Macrovascular endothelial function data displayed as mean \pm standard deviation, with $P$ values from $t$ tests. *Significant at $P<0.05 ;{ }^{* *}$ significant after Bonferroni adjustment for eight comparisons at $P<0.006$. ACh, acetylcholine; SNP, sodium nitroprusside; FMD, flow-mediated dilatation; GTN, glyceryl-trinitrate mediated dilatation. 
The strengths of the present work are the inclusion of a large sample of patients, which provided adequate statistical power for the analysis. Additionally, measurements of microvascular and macrovascular endothelium-dependent and -independent function, along with assessments of arteriosclerosis and carotid atherosclerosis allowed detailed characterisation of each stage of atherosclerosis. However, some limitations include the cross-sectional study design, which does not determine cause-effect relationships. Further prospective studies are required to see which measures of endothelial function and vascular morphology are able to predict the development of future cardiac events.

In conclusion, the present work highlights that, with the exception of macrovascular endothelium-independent function, assessments of vascular function and morphology cannot be used interchangeably to assess vascular health. Examination of endothelial function should incorporate functional and morphological assessments to provide information on global endothelial dysfunction.

\begin{abstract}
Abbreviations
ACh: acetylcholine; Alx: augmentation index; CAD: coronary artery disease; CIMT: carotid intima-media thickness; CVD: cardiovascular disease; CV: coefficient of variation; ED: endothelial dysfunction; ET-1: endothelin-1; FMD: flow-mediated dilatation; GTN: glyceryl-trinitrate-mediated dilatation; NO: nitric oxide; PWA: pulse wave analysis; PWV: pulse wave velocity; RA: rheumatoid arthritis: SNP: sodium nitroprusside.
\end{abstract}

\section{Competing interests}

The authors declare that they have no competing interests.

\section{Authors' contributions}

AS participated in the design of the study, recruited patients, performed the vascular assessments, conducted data analysis and drafted the manuscript. $\mathrm{JH}$ performed the statistical analysis. KD participated in the design of the study. JPS performed laboratory analysis of blood samples. GK participated in the design of the study and helped with drafting the manuscript. All authors have read and approved the final manuscript.

\section{Acknowledgements}

The authors would like to thank Dr. George Balanos for his help and assistance with the flow-mediated dilatation assessment.

\section{Authors' details \\ 'Department of Rheumatology, Dudley Group of Hospitals NHS Trust, Russells Hall Hospital, Pensnett Road, Dudley, DY1 2HQ, UK. ${ }^{2}$ School of Sport and Exercise Sciences, University of Birmingham, Edgbaston, Birmingham, B15 2TT, UK. ${ }^{3}$ Arthritis Research UK Epidemiology Unit, University of Manchester, Oxford Road, Manchester, M13 9PT, UK. ${ }^{4}$ Wolfson Computer Laboratory, University Hospital Birmingham NHS Foundation Trust, Queen Elizabeth Hospital Birmingham, Mindelsohn Way, Birmingham, B15 2WB.}

Received: 8 March 2013 Revised: 28 March 2013

Accepted: 6 September 2013 Published: 6 September 2013

\section{References}

1. Sandoo A, van Zanten JJ, Metsios GS, Carroll D, Kitas GD: The endothelium and its role in regulating vascular tone. Open Cardiovasc Med J 2010, 4:302-312.

2. Lerman A, Zeiher AM: Endothelial Function: Cardiac Events. Circulation 2005, 111:363-368.

3. Wort SJ, Woods M, Warner TD, Evans TW, Mitchell JA: Endogenously Released Endothelin-1 from Human Pulmonary Artery Smooth Muscle
Promotes Cellular Proliferation. Relevance to Pathogenesis of Pulmonary Hypertension and Vascular Remodeling. Am J Respir Cell Mol Biol 2001, 25:104-110.

4. Vanhoutte PM: Say NO to ET. J Auton Nerv Syst 2000, 81:271-277.

5. Kubes P, Suzuki M, Granger DN: Nitric oxide: an endogenous modulator of leukocyte adhesion. Proc Natl Acad Sci USA 1991, 88:4651-4655.

6. Nong Z, Hoylaerts M, Van Pelt N, Collen D, Janssens S: Nitric Oxide Inhalation Inhibits Platelet Aggregation and Platelet-Mediated Pulmonary Thrombosis in Rats. Circ Res 1997, 81:865-869.

7. Ghitescu L, Robert M: Diversity in unity: the biochemical composition of the endothelial cell surface varies between the vascular beds. Microsc Res Tech 2002, 57:381-389.

8. Anderson TJ, Uehata A, Gerhard MD, Meredith IT, Knab S, Delagrange D, Lieberman EH, Ganz P, Creager MA, Yeung AC: Close relation of endothelial function in the human coronary and peripheral circulations. J Am Coll Cardiol 1995, 26:1235-1241.

9. Takase B, Hamabe A, Satomura K, Akima T, Uehata A, Ohsuzu F, Ishihara M, Kurita $A$ : Close relationship between the vasodilator response to acetylcholine in the brachial and coronary artery in suspected coronary artery disease. International Journal of Cardiology 2005, 105:58-66.

10. Khan F, Patterson D, Belch JJ, Hirata K, Lang CC: Relationship between peripheral and coronary function using laser Doppler imaging and transthoracic echocardiography. Clin Sci (Lond) 2008, 115:295-300.

11. Hingorani AD, Cross J, Kharbanda RK, Mullen MJ, Bhagat K, Taylor M, Donald AE, Palacios M, Griffin GE, Deanfield JE, MacAllister RJ, Vallance P: Acute systemic inflammation impairs endothelium-dependent dilatation in humans. Circulation 2000, 102:994-999.

12. Sandoo A, Veldhuijzen van Zanten JJCS, Metsios GS, Carroll D, Kitas GD: Vascular function and morphology in rheumatoid arthritis: a systematic review. Rheumatology 2011, 50:2125-39.

13. Wilkinson IB, Hall IR, MacCallum H, Mackenzie IS, McEniery CM, van der Arend BJ, Shu YE, MacKay LS, Webb DJ, Cockcroft JR: Pulse-Wave Analysis: Clinical Evaluation of a Noninvasive, Widely Applicable Method for Assessing Endothelial Function. Arterioscler Thromb Vasc Biol 2002, 22:147-152.

14. Zieman SJ, Melenovsky V, Kass DA: Mechanisms, pathophysiology, and therapy of arterial stiffness. Arterioscler Thromb Vasc Biol 2005, 25:932-943.

15. Wilkinson IB, Qasem A, McEniery CM, Webb DJ, Avolio AP, Cockcroft JR: Nitric oxide regulates local arterial distensibility in vivo. Circulation 2002, 105:213-217.

16. Nichols WW: Clinical measurement of arterial stiffness obtained from noninvasive pressure waveforms. American Journal of Hypertension 2005, 18:3-10.

17. Saito M, Okayama H, Nishimura K, Ogimoto A, Ohtsuka T, Inoue K, Hiasa G, Sumimoto T, Higaki J: Possible link between large artery stiffness and coronary flow velocity reserve. Heart 2008, 94:e20.

18. Wohlin M, Helmersson J, Sundstrom J, Arnlov J, Vessby B, Larsson A, Andren B, Lind L, Basu S: Both cyclooxygenase- and cytokine-mediated inflammation are associated with carotid intima-media thickness. Cytokine 2007, 38:130-136.

19. Corrado E, Rizzo M, Coppola G, Muratori I, Carella M, Novo S: Endothelial dysfunction and carotid lesions are strong predictors of clinical events in patients with early stages of atherosclerosis: a 24-month follow-up study. Coron Artery Dis 2008, 19:139-144.

20. Aubry MC, Maradit-Kremers H, Reinalda MS, Crowson CS, Edwards WD, Gabriel SE: Differences in atherosclerotic coronary heart disease between subjects with and without rheumatoid arthritis. J Rheumatol 2007, 34:937-942.

21. Maini RN: Rheumatoid arthritis. A paradigm of inflammatory disease of the musculoskeletal system. Acta Orthop Scand Supp/ 1998, 281:6-13.

22. Sattar N, McCarey DW, Capell H, McInnes IB: Explaining how "high-grade" systemic inflammation accelerates vascular risk in rheumatoid arthritis. Circulation 2003, 108:2957-2963.

23. Arosio E, De MS, Rigoni A, Prior M, Delva P, Lechi A: Forearm haemodynamics, arterial stiffness and microcirculatory reactivity in rheumatoid arthritis. J Hypertens 2007, 25:1273-1278.

24. Soltesz P, Der H, Kerekes G, Szodoray P, Szucs G, Danko K, Shoenfeld Y, Szegedi G, Szekanecz Z: A comparative study of arterial stiffness, flowmediated vasodilation of the brachial artery, and the thickness of the carotid artery intima-media in patients with systemic autoimmune diseases. Clin Rheumatol 2009, 28:655-662. 
25. Kerekes G, Szekanecz Z, Der H, Sandor Z, Lakos G, Muszbek L, Csipo I, Sipka S, Seres I, Paragh G, Kappelmayer J, Szomjak E, Veres K, Szegedi G, Shoenfeld $Y$, Soltesz P: Endothelial dysfunction and atherosclerosis in rheumatoid arthritis: a multiparametric analysis using imaging techniques and laboratory markers of inflammation and autoimmunity. J Rheumatol 2008, 35:398-406.

26. Kerekes G, Soltesz P, Der H, Veres K, Szabo Z, Vegvari A, Szegedi G, Shoenfeld $Y$, Szekanecz $Z$ : Effects of rituximab treatment on endothelial dysfunction, carotid atherosclerosis, and lipid profile in rheumatoid arthritis. Clin Rheumatol 2009, 28:705-710.

27. Komai N, Morita Y, Sakuta T, Kuwabara A, Kashihara N: Anti-tumor necrosis factor therapy increases serum adiponectin levels with the improvement of endothelial dysfunction in patients with rheumatoid arthritis. Mod Rheumatol 2007, 17:385-390.

28. Sidiropoulos PI, Siakka P, Pagonidis K, Raptopoulou A, Kritikos H, Tsetis D, Boumpas DT: Sustained improvement of vascular endothelial function during anti-TNFalpha treatment in rheumatoid arthritis patients. Scand J Rheumatol 2009, 38:6-10.

29. Yeboah J, Burke GL, Crouse JR, Herrington DM: Relationship between brachial flow-mediated dilation and carotid intima-media thickness in an elderly cohort: the Cardiovascular Health Study. Atherosclerosis 2008, 197:840-845

30. Koivistoinen $T$, Virtanen M, Hutri-Kahonen N, Lehtimaki T, Jula A, Juonala M, Moilanen L, Aatola H, Hyttinen J, Viikari JS, Raitakari OT, Kahonen M: Arterial pulse wave velocity in relation to carotid intima-media thickness, brachial flow-mediated dilation and carotid artery distensibility: the Cardiovascular Risk in Young Finns Study and the Health 2000 Survey. Atherosclerosis 2012, 220:387-393.

31. Irace C, Fiaschi E, Cortese C, Gnasso A: Flow-mediated vasodilatation of the brachial artery and intima-media thickness of carotid artery in never-treated subjects. Int Angiol 2006, 25:274-279.

32. Yan RT, Anderson TJ, Charbonneau F, Title L, Verma S, Lonn E, on behalf of the FATE Investigators: Relationship Between Carotid Artery Intima-Media Thickness and Brachial Artery Flow-Mediated Dilation in Middle-Aged Healthy Men. J Am Coll Cardiol 2005, 45:1980-1986.

33. Simova I, Denchev S: Endothelial functional and structural impairment in patients with different degrees of coronary artery disease development. Heart Vessels 2008, 23:308-315.

34. Furumoto T, Fujii S, Saito N, Mikami T, Kitabatake A: Relationships between brachial artery flow mediated dilation and carotid artery intima-media thickness in patients with suspected coronary artery disease. Jpn Heart J 2002, 43:117-125.

35. Stokes KY, Granger DN: The microcirculation: a motor for the systemic inflammatory response and large vessel disease induced by hypercholesterolaemia? J Physiol 2005, 562:647-653.

36. Adams MR, Robinson J, McCredie R, Seale JP, Sorensen KE, Deanfield JE, Celermajer DS: Smooth muscle dysfunction occurs independently of impaired endothelium-dependent dilation in adults at risk of atherosclerosis. J Am Coll Cardiol 1998, 32:123-127.

37. Ghiadoni L, Magagna A, Kardasz I, Taddei S, Salvetti A: Fixed Dose Combination of Perindopril and Indapamide Improves Peripheral Vascular Function in Essential Hypertensive Patients. Am J Hypertens 2009, 22:506-512.

38. Sandoo A, Kitas GD, Carroll D, Veldhuijzen van Zanten JJ: The role of Inflammation \& Cardiovascular Disease Risk on Microvascular and Macrovascular Endothelial Function in Patients with Rheumatoid Arthritis: a Cross-sectional and Longitudinal Study. Arthritis Res Ther 2012, 14:R117.

39. Rohani M, Jogestrand T, Kallner G, Jussila R, Agewall S: Morphological changes rather than flow-mediated dilatation in the brachial artery are better indicators of the extent and severity of coronary artery disease. J Hypertens 2005, 23:1397-1402.

40. Arnett FC, Edworthy SM, Bloch DA, McShane DJ, Fries JF, Cooper NS, Healey LA, Kaplan SR, Liang MH, Luthra HS: The American Rheumatism Association 1987 revised criteria for the classification of rheumatoid arthritis. Arthritis Rheum 1988, 31:315-324.

41. Prevoo ML, Van 't Hof MA, Kuper HH, Van Leeuwen MA, van de Putte LB, van Riel PL: Modified disease activity scores that include twenty-eightjoint counts. Development and validation in a prospective longitudinal study of patients with rheumatoid arthritis. Arthritis Rheum 1995, 38:44-48.
42. Turner J, Belch JJ, Khan F: Current concepts in assessment of microvascular endothelial function using laser Doppler imaging and iontophoresis. Trends Cardiovasc Med 2008, 18:109-116.

43. Sandoo A, Veldhuijzen van Zanten JJ, Metsios GS, Carroll D, Kitas GD: The Endothelium and Its Role in Regulating Vascular Tone. The Open Cardiovascular Medicine Journal 2010, 4:302-312.

44. Corretti MC, Anderson TJ, Benjamin EJ, Celermajer D, Charbonneau F, Creager MA, Deanfield J, Drexler H, Gerhard-Herman M, Herrington D, Vallance P, Vita J, Vogel R: Guidelines for the ultrasound assessment of endothelial-dependent flow-mediated vasodilation of the brachial artery: a report of the International Brachial Artery Reactivity Task Force. J Am Coll Cardiol 2002, 39:257-265.

45. Sandoo A, Protogerou AD, Hodson J, Smith JP, Zampeli E, Sfikakis PP, Kitas GD: The role of inflammation, the autonomic nervous system and classical cardiovascular disease risk factors on subendocardial viability ratio in patients with RA: a cross-sectional and longitudinal study. Arthritis Res Ther 2012, 14:R258.

46. Touboul PJ, Hennerici MG, Meairs S, Adams H, Amarenco P, Bornstein N, Csiba L, Desvarieux M, Ebrahim S, Hernandez HR, Jaff M, Kownator S, Naqvi T, Prati P, Rundek T, Sitzer M, Schminke U, Tardif JC, Taylor A, Vicaut E, Woo KS: Mannheim carotid intima-media thickness and plaque consensus (2004-2006-2011). An update on behalf of the advisory board of the 3rd, 4th and 5th watching the risk symposia, at the 13th, 15th and 20th European Stroke Conferences, Mannheim, Germany, 2004, Brussels, Belgium, 2006, and Hamburg, Germany, 2011. Cerebrovasc Dis 2012, 34:290-296.

47. Pignoli P, Tremoli E, Poli A, Oreste P, Paoletti R: Intimal plus medial thickness of the arterial wall: a direct measurement with ultrasound imaging. Circulation 1986, 74:1399-1406.

48. Liang Q, Wendelhag I, Wikstrand J, Gustavsson T: A multiscale dynamic programming procedure for boundary detection in ultrasonic artery images. IEEE Trans Med Imaging 2000, 19:127-142.

49. Sodergren A, Karp K, Boman K, Eriksson C, Lundstrom E, Smedby T, Soderlund L, Rantapaa-Dahlqvist S, Wallberg-Jonsson S: Atherosclerosis in early rheumatoid arthritis: very early endothelial activation and rapid progression of intima media thickness. Arthritis Res Ther 2010, 12:R158.

50. Lunder M, Janic M, Kejzar N, Sabovic M: Associations among different functional and structural arterial wall properties and their relations to traditional cardiovascular risk factors in healthy subjects: a crosssectional study. BMC Cardiovasc Disord 2012, 12:29.

51. Irace C, Fiaschi E, Cortese C, Gnasso A: Flow-mediated vasodilatation of the brachial artery and intima-media thickness of carotid artery in never-treated subjects. Int Angiol 2006, 25:274-279.

52. Juonala M, Viikari JS, Laitinen T, Marniemi J, Helenius H, Ronnemaa T, Raitakari OT: Interrelations between brachial endothelial function and carotid intima-media thickness in young adults: the cardiovascular risk in young Finns study. Circulation 2004, 110:2918-2923.

53. Hashimoto M, Eto M, Akishita M, Kozaki K, Ako J, lijima K, Kim S, Toba K, Yoshizumi M, Ouchi Y: Correlation between flow-mediated vasodilatation of the brachial artery and intima-media thickness in the carotid artery in men. Arterioscler Thromb Vasc Biol 1999, 19:2795-2800.

54. Enderle MD, Schroeder S, Ossen R, Meisner C, Baumbach A, Haering HU, Karsch KR, Pfohl M: Comparison of peripheral endothelial dysfunction and intimal media thickness in patients with suspected coronary artery disease. Heart 1998, 80:349-354.

55. Ravikumar R, Deepa R, Shanthirani C, Mohan V: Comparison of carotid intima-media thickness, arterial stiffness, and brachial artery flow mediated dilatation in diabetic and nondiabetic subjects (The Chennai Urban Population Study [CUPS-9]). Am J Cardiol 2002, 90:702-707.

56. Toutouzas K, Sfikakis PP, Karanasos A, Aggeli C, Felekos I, Kitas G, Zampeli E, Protogerou A, Stefanadis C: Myocardial ischaemia without obstructive coronary artery disease in rheumatoid arthritis: hypothesis-generating insights from a cross-sectional study. Rheumatology (Oxford) 2013, 52:76-80.

57. Krentz AJ, Clough G, Byrne CD: Interactions between microvascular and macrovascular disease in diabetes: pathophysiology and therapeutic implications. Diabetes Obes Metab 2007, 9:781-791.

58. Sandoo A, Carroll D, Metsios GS, Kitas GD, Veldhuijzen van Zanten JJ: The association between microvascular and macrovascular endothelial function in patients with rheumatoid arthritis: a cross-sectional study. Arthritis Res Ther 2011, 13:R99. 
59. Oren A, Vos LE, Uiterwaal CSPM, Grobbee DE, Bots ML: Cardiovascular Risk Factors and Increased Carotid Intima-Media Thickness in Healthy Young Adults: The Atherosclerosis Risk in Young Adults (ARYA) Study. Arch Intern Med 2003, 163:1787-1792.

60. Van Doornum S, McColl G, Jenkins A, Green DJ, Wicks IP: Screening for atherosclerosis in patients with rheumatoid arthritis: comparison of two in vivo tests of vascular function. Arthritis Rheum 2003, 48:72-80.

doi:10.1186/ar4287

Cite this article as: Sandoo et al.: The association between functional and morphological assessments of endothelial function in patients with rheumatoid arthritis: a cross-sectional study. Arthritis Research \& Therapy 2013 15:R107.

\section{Submit your next manuscript to BioMed Central} and take full advantage of:

- Convenient online submission

- Thorough peer review

- No space constraints or color figure charges

- Immediate publication on acceptance

- Inclusion in PubMed, CAS, Scopus and Google Scholar

- Research which is freely available for redistribution

Submit your manuscript at www.biomedcentral.com/submit 